\title{
Complexity and Hybrid Public Administration-Theoretical and Empirical Challenges
}

\author{
Tom Christensen • Per Lagreid
}

Published online: 7 October 2010

C The Author(s) 2010. This article is published with open access at Springerlink.com

\begin{abstract}
This article provides a greater understanding of hybrid public administration. Different generations of public sector reforms have accentuated hybrid and complex features of public organizations, resulting in multiple-layer structural and cultural features. The article covers the following research questions: 1) how can we interpret the increasing tendency towards hybrid administration in terms of a transformative approach; 2) how is hybrid administration developing out of attempts to balance NPM and post-NPM?; and 3) how can we understand the major mechanisms producing hybridity in a modern reform? The case we focus on is the reform of the Norwegian welfare administration.
\end{abstract}

Keywords Hybrid - Complexity - New Public Management - Administrative reform · Post-NPM $\cdot$ Norway $\cdot$ Welfare adminsitration reform

\section{Introduction}

There is a growing complexity in modern organizations with implications for public, private and non-profit sectors around the world (Farazmand 2002). Public organizations are becoming increasingly complex and hybrid as they try to attend to numerous and sometimes conflicting ideas, considerations, demands, structures and cultural elements at the same time. One reason for this is that modern

\footnotetext{
T. Christensen

Department of Political Science, University of Oslo, P.O. Box 1097, 0317 Oslo, Norway e-mail: Tom.Christensen@stv.uio.no

P. Lægreid $(\bowtie)$

Department of Administration and Organization Theory, University of Bergen, Christiegt 17, 5007

Bergen, Norway

e-mail: Per.Lagreid@aorg.uib.no
} 
representative democracies are institutionalizing administrative policies and implementing different generations of modern public sector reforms at an accelerating pace (Light 1997; Lynn 2006). The NPM reform wave, seen as a reaction to the challenges and problems of the 'old public administration', and the post-NPM reform wave, seen partly as a reaction to the negative effects of NPM, are together resulting in a complex sedimentation or layering of structural and cultural features (Olsen 2009; Streeck and Thelen 2005). In the course of this process certain elements of structure and culture have remained relatively stable, others have become stronger or even institutionalized, and others still have been weakened or deinstitutionalized (Røvik 1996).

The purpose of this article is to provide a greater understanding of hybrid administration within the context of NPM and post-NPM reforms. Even though there is an overall understanding in the literature about increasing complexity and hybridity in public sector reforms, the mechanisms of this development are more poorly understood. Through a theoretically exploratory study, we will empirically discuss the mechanisms, processes and challenges of complexity and hybridity by focusing on the classical distinction between political and administrative control on the one hand, and institutional autonomy on the other, and relate this to the NPM and post-NPM reforms. Whereas NPM as a reform wave was driven very much by the autonomy argument, stressing structural devolution and increased distance to executive politicians, post-NPM reforms have tended to revive the control and coordination aspects (Gregory 2003). The NPM reforms combined vertical specialization or structural devolution with extensive use of the principle of 'single-purpose organizations' or horizontal specialization, creating a fragmented system which, it was argued, catered to 'role purity' (Gregory 2001). Post-NPM reforms, which started in the late 1990s in the countries that had been NPM trail-blazers, introduced a combination of vertical integration via stronger control measures and greater capacity for the political executive, and more horizontal collaboration and coordination in the form of networks, teams and projects (Halligan 2006).

The article will accordingly cover the following main research questions:

a) analytically, how can we understand the mechanisms related to increasing complex and hybrid administration? Here we base our discussion on a transformative approach (Christensen and Lægreid 2001a; Pollitt and Bouckaert 2004). We ask how a dynamic interaction of structure, culture and environmental factors may explain increasing complexity and hybridization.

b) empirically, how is complex and hybrid administration developing out of attempts to balance NPM and post-NPM considerations.

c) based on the transformative approach and insights into the dynamics of modern public sector reforms in general, how can we understand the mechanisms of complexity and hybridity in a specific modern reform.

The case we focus on is the largest public sector reform ever in Norway, the reform of the welfare administration. This reform comprised a merger between the employment and pension agencies and local partnerships between this new organization and the social services of the municipalities (Christensen et al. 2007). The data here are based on personal interviews with elite actors, public documents and major evaluatory studies of the reform. 
First, we will give a brief overview of what we mean by complexity and hybridity, followed by a lengthy discussion based on a transformative approach and focus especially on the mechanisms leading to more complexity and hybridity. Second, we will describe how NPM and post-NPM reforms have tended to increase complexity and hybridization concerning balancing control and autonomy. Third, we will use the reform of the Norwegian welfare administration to show how attempts to balance control and autonomy bring about complexity and hybridity. Finally, we will draw some conclusions and point to some implications.

\section{Complexity and hybridity}

Complexity in public organizations may mean different things. In this article we are not following the rather abstract and very general definitions of prominent complexity theorists (Pollitt 2009; Teisman et al. 2009) but we are focusing on some central aspects, i.e. structural and cultural complexity. Organization theory has treated complexity as a structural variable differentiating between vertical and horizontal complexity (Anderson 1999; Daft 1992). In line with this thinking structural complexity in public organizations may be measured according to some central dimensions. One is vertical specialization, another is horizontal specialization, and both dimensions have intra- and inter-organizational elements (Egeberg 2003; Gulick 1937; Simon 1957). Vertical, intra-organizational specialization tells us how formal authority is distributed among different levels of the hierarchy. Strong vertical specialization means that hierarchical control and coordinative power are divided among many leaders and levels. Vertical interorganizational specialization focuses on the specialization among public organizations. Used in this sense strong vertical specialization may mean ministries with a lot of subordinate agencies, while weak specialization indicates more integrated ministries.

Horizontal intra-organizational specialization means internal specialization within public organizations - the division of an organization into different departments and units, according to principles that Gulick (1937) labels purpose, process, clientele and geography. Strong horizontal specialization indicates division into several subunits. Horizontal inter-organizational specialization focuses on specialization among public organizations on the same hierarchical level, as, for example, among ministries or agencies. If we look at all these dimensions together we get an indication of how complex a system is. One extreme is strong vertical and horizontal specialization overall, meaning strong proliferation and fragmentation, which has been typical for the NPM reforms (Pollitt and Bouckaert 2004); the other is low specialization on both dimensions, indicating an integrated political-administrative system, like the 'old public administration' in many countries or reflecting the emerging post-NPM reforms (Christensen and Lægreid 2007a). Rather than measuring complexity specifically, we will use these dimensions to determine in what direction reforms are moving.

Cultural complexity is also part of the equation, but more difficult to grasp. Strong cultural complexity means that there are a variety of informal, cultural norms 
and values in and among public organizations, because there are many considerations to attend to, or because sub-cultures have developed or else because cultural norms from different types of reforms have been combined. Weak cultural complexity means cultural homogeneity and integration-i.e., members of an organization are very committed to its basic cultural norms and values and there is a common sense of purpose and a feeling of being in the same 'cultural boat' (Kaufman 1960; Krasner 1988; March and Olsen 1989; Selznick 1957).

Hybridity in the public sector may also mean different things. For some the concept is similar to complexity. For others they denote different structural and cultural dimensions or features existing together. Hybrid organizations can for example signify quasi-governmental organizations that exist at the interface between the public and private sector (Lan and Rainey 1992), which may be either market or civil society organizations (Koppell 2003); the mixture of market and hierarchy (Williamson 1991); the combination of political advocacy and service provision (Minkoff 2002); or the mixture of different structural forms inside the ministry, in relation to agencies, state-owned enterprises and regional and local government (Kickert 2001; Pollitt et al. 2007). Hybrid is also the term used to characterize different cultural elements like professional cultures in different parts of government.

We distinguish between complexity and hybridity. The former has a structural dimension addressing vertical and horizontal specilization and a cultural dimension addressing the varity of informal norms and values. The latter addressing the potential tension or inconsistency between diverse structural and cultural elements in government. Hybrid organizations are multifunctional entities combining different tasks, values and organizational forms. They are composite and compounded arrangements that are combining partly inconsistent considerations producing difficult and unstable trade-offs and lasting tensions. The mechanisms producing such tensions are analytically discussed, connected more specifically to the tension between political-administrative control and institutional autonomy in combining different generations of modern, public reforms, and exemplified by a large public reform in Norway.

\section{A transformative approach and preconditions for developing complexity}

Main elements of the transformative approach

According to a transformative approach, public actors involved in reform processes are constrained and influenced by three sets of factors or contexts - polity features, historical institutional context and environmental pressure-seen through a structural-instrumental, cultural and environmental perspective respectively (Christensen and Lægreid 2001a, 2007b; Pollitt and Bouckaert 2004). These factors define how much leeway political leaders have in making choices about a conscious design of complexity in public reforms (Olsen 1992). This includes how they are able to balance and making trade-offs between central concerns in NPM and postNPM reforms like central political and administrative control on the one hand, and agency and professional autonomy on the other, relating to tensions of hybridity. 
A structural-instrumental perspective

Structural, constitutional and polity factors related to a structural-instrumental perspective go some way to explaining how leaders handle reform processes (Weaver and Rockman 1993; Olsen 1992). These constraints may be very tight, potentially giving leaders strong hierarchical control but not much leeway or flexibility. But they might also be rather loose, not giving leaders and other actors much direction but instead a lot of potential discretionary influence. The structural context influence not only the reform process but indirectly the trade-offs between different considerations and therefore the resulting structural content that potentially may be both complex and hybrid.

From a structural/instrumental point of view, reforms may generally be seen as conscious organizational design or reorganization, i.e. political and administrative leaders use the structure as an instrument to fulfil goals (Egeberg 2003). Major preconditions for this are that the leaders have a relatively large degree of control over reform processes and that they score high on rational calculation or means-end thinking (see Dahl and Lindblom 1953). The first question is therefore why, to what extent and how leaders can design complexity so as to achieve a balance between control and autonomy, i.e. what are the mechanisms working here. A rather simple answer is that this is seen as the most rational solution to the challenges confronting the public organization (March and Olsen 1983). So there is congruence between complex constraints and complex structure or reforms (see Lawrence and Lorsch 1967).

Second, complexity may signal flexibility on the part of the leaders. Complexity might mean a more loosely coupled organization (March and Olsen 1976). Leaders may use myths and symbols to balance control and autonomy, pretending to some audiences that the control side is important, while others will hear the autonomy message. Or have certain parts of the organization specializing in control, while others focus on autonomy (Brunsson 1989; Cyert and March 1963). Flexibility potentially means increasing hybridity and potential tensions.

Heterogeneity inside government, diverse institutionally based interests and a tugof-war between different leaders may also create the background for organizational complexity (Allison 1971). There could also be a 'sequential attention to goals and quasi-solutions of conflicts', implying that control may be emphasized at one point in time, to cater to some actors, while autonomy becomes predominant at other times, to cater to other constituencies, without any overall thought for consistency (Cyert and March 1963).

\section{A cultural perspective}

According to a cultural perspective public organizations develop core informal norms and values slowly in an institutionalization process, leading them to evolve distinct cultures (Scott 2007; Selznick 1957). Different countries and government institutions have different historical-cultural traditions or 'roots' and their reforms are 'path dependent', meaning that national reforms have unique features (Krasner 1988; March and Olsen 1989). When public organizations are exposed to reform processes, the reforms proposed must go through a cultural compatibility test. The greater the consistency between the values underlying the reforms and the values on 
which the existing administrative system is based, the more likely the reforms are to be successful (Brunsson and Olsen 1993).

In principle the development of common cultures in public organizations should decrease complexity, particularly if culture is the 'institutional glue' that holds an organization together or if culture means a lot for organizational development (March and Olsen 1989). So how could complexity then be related to cultural development? One answer is that even if a culture is seen as common, it is also complex, reflecting a variety of informal norms and values. If we move away from the premise of cultural homogeneity, we can also argue that complexity in public organizations may reflect different sub-cultures. Even though there are major common cultural features, there is also cultural diversity. So complexity may result from simultaneously catering to sub-cultures favoring control and autonomy.

Cultural complexity may enhance hybridity. Diverse sub-cultures may point to different informal norms and values that are not easily compatible, but the common cultural features are harnessing them. Another mechanism may be that there are competing types of cultural appropriateness existing side by side in the public sector (Boin and Christensen 2008). This means that central political and administrative leaders may have different cultural norms and values related to balancing control and autonomy relative to subordinate institutions or professional groups in the civil service.

\section{An environmental perspective}

A third set of factors relates to an environmental perspective. According to Meyer and Rowan (1977) the environment of public organizations may be divided into two parts, the technical and the institutional environment. The technical environment is mainly about efficiency, production and exchange. The technical environment may exert strong external determinism, meaning that an organization has to adapt to demands from the environment (Olsen 1992). The institutional environment has a less instrumental character and is more about assumptions concerning the appropriate organizational structure, internal culture, recruitment policy, demography, etc.

The technical environment for modern governmental organizations is diverse and possibly turbulent, which would be reflected in internal complexity (Scott and Davies 2006). Public organization will grow more complex because the demands on the organization from outside sources have become more complex. Balancing control and autonomy could be the result of attending to different actors and institutions in the technical environment, which may not always be easy to reconcile.

Reform myths coming from the institutional environment are linked to the cognitive institutional pillar and in general believed to have the effect of making public organizations isomorphic (DiMaggio and Powell 1983; Meyer and Rowan 1977; Scott 2007). The argument behind this is that myths develop in the institutional environment and spread rather quickly to other populations of organizations, where they primarily function as 'window-dressing', creating an image of the organization that increases its legitimacy (Brunsson 1989; Czarniawska and Sevón 1996). The argument is that the cognitive pillar addressing the legitimacy issue is an important force of institutionalization (Scott 2007). 
Some scholars believe that myths are created and spread consciously by certain groups from different organizational fields (Sahlin-Anderson 2001). These are often labeled 'institutional standards' or 'prescriptions'. These institutional standards are sometimes used in conflict with other myths or practices, through processes of partial imitation, editing and translation (Røvik 2002). Thus, increased complexity has to do with public organizations imitating and using diverse institutional standards (Lægreid et al. 2007). Complexity and hybridity could result from organizations combining different reform elements containing both control and autonomy measures (Røvik 2002). Pragmatic adaptation to reforms, whereby countries, sectors and organizations pick institutional standards from organizational fields and combine them in a 'patch-work-like' way, may result in hybridity among reform elements.

On the one hand, regulative demands from technical environment may influence both the institutional environment and the internal culture. Strong regulative pressure may both lead to intensive use of reform symbols, to increase the likelihood an instrumental implementation of the reforms, and lead to a changing internal culture (Sahlin-Andersson 1996, 2001). The regulative environment and also broader stream-based institutional environment feed in and constrain the cognitive promotion of the new culture linked to the reform (Farazmand 2002; Scott 2007). On the other hand, the cognitive elements of the institutional environment may have the upper hand relative to the technical environment and lead to shallow and symbolical reform features. Both these options may increase the legitimacy of the leadership and the public organization more in general (Brunsson 1989).

Based on this way of reasoning, complexity may result from dynamically combining influence from technical and institutional environments (Christensen and Lægreid 2001b). The pressure for more or less control and autonomy may be consistent, but also diverse, eventually resulting in hybridity.

The dynamics of the transformative approach

There is a dynamic relationship between the reform features described in the three views stated, and an important question is how much political leeway they offer concerning designing a balance between control and autonomy. Will this eventuality make complexity into hybridity?

The hierarchical design of complexity may be either strengthened or modified by the other contexts represented by the three supplementary perspectives. In the best of all worlds, political and administrative leaders will further a reform catering to a complex balance between control and autonomy, and they will receive support from a variety of different stakeholders, thus increasing the reform's legitimacy. Furthermore, they will be supported by cultural norms and values and symbols that present the complex design as modern and good. At the other extreme, hierarchical based design of complexity may become mired in complex negotiations, may encounter a resistant culture and unwilling professions, and may have to deal with counter-myths, resulting in a lot of incoherent hybridity. In reality, as we often discover in comparative reform studies, hierarchically controlled reform usually has less difficulty controlling the participants than the problems and solutions (Christensen and Lægreid 2001b, 2007a; Pollitt and Bouckaert 2004). Relatively 
often heterogeneity is used to enhance hierarchical control, or compromises are struck that make it possible to stay the course. Leaders often have the upper hand in manipulating symbols, but not always enough to stop cultural resistance. Concerning the access structure, the structure of problems and solutions, leaders often have problems either of defining clearly what they would like to do or in anticipating the effects of the reforms they propose. This leads not only to more frequent new reforms, because 'shallow' reforms are unsustainable, but to an ever growing hybridity in government.

\section{NPM and post-NPM reforms: increasing complexity and hybridization}

When New Public Management was introduced in the early 1980s in Australia and New Zealand it was intended as an alternative to and confrontation with 'old public administration', which was seen as representing a centralized, integrated and big government model (Gregory 2001; Halligan 2001). The main message from the NPM entrepreneurs, often with clear ideological and symbolic overtones, was that governments and public sectors around the world not only had to be scaled back, but also fundamentally restructured, often based on a combination of market- and management theories. ${ }^{1}$ The structural model proposed was one of increased specialization and increased fragmentation, both vertically and horizontally (Boston et al. 1996). Vertically it was argued that structural devolution was the answer to central capacity problems, because it would allow leaders to focus on more strategic questions and frame steering. There were many new forms of structural devolution: giving traditionally agencies more leeway, i.e. moving them further away from the political executive and/or relaxing certain rules constraining their activities; establishing more regulatory agencies with strong autonomy based on professional values; giving state-owned enterprises strong autonomy, with a lot of barriers to political involvement; and giving greater priority to market values. Other measures included privatizing public activities related to service and the market, which often involved reorganizing agencies or public enterprises. Taken together these NPM reform ideas amounted to a rather fragmented model that swung the balance in favor of autonomy and created a good deal more complexity and potential hybridity. This created problems of political control, as shown in comparative reform studies, even though the main argument from supporters of NPM has been that political control should not weaken, but work through other mechanisms (Christensen and Lægreid 2001b; Pollitt and Bouckaert 2004).

It is well documented that NPM has been a rather complex and mixed bag of reforms. Boston et al. (1996) show that the underlying economic ideas of NPM reform informed by new institutional economic theories were both ambiguous and contradictory, which increased the probability of both complexity and hybridity. They point out that there were both centralizing and devolutionary elements in these theories. Some of the centralizing ideas were related to theories on contracts, which

\footnotetext{
${ }^{1}$ We do not pretend to present and discuss NPM in any broad way, with all it's different elements including user-friendliness and efficiency, but focus mostly on it's structural features and it's view on balancing control and autonomy.
} 
were seen as necessary to give the central leaders some control after structural devolution. And during the last two decades of NPM it has become increasingly clear that devolution and deregulation have been coupled with re-regulation and more scrutiny and control. The biggest flaws of NPM were probably its efforts to divorce management from policy (Kettl 2006).

When the first post-NPM measures emerged in Australia and New Zealand in the late 1990s, they were primarily seen as a reaction to the effects and implications of NPM-related reforms (Gregory 2003; Halligan 2007). Two types of challenges seemed to be important. One was the undermining of control and central capacity that NPM had brought. Now it was time for the executive politicians to take back some of that control and increase their own capacity to solve societal problems. The measures used were to vertically integrate some of the agencies and enterprises again, either by dissolving some agencies and integrating their activities in the ministries, or by establishing more controls and imposing more constraints on the agencies and state-owned enterprises. Another measure was to strengthen central political capacity by employing more political advisors at the ministries and PM's offices. Other factors that led to the 'whole-of-government' efforts were problems with delivering on the promise of increased efficiency and concerns after 9/11 about terrorist threats or other global problems, like tsunamis and pandemics (Christensen and Lægreid 2007a).

The horizontal challenge was seen as even more important than the vertical, because having a lot of sectoral pillars or silos was seen as obstructing the solution of cross-sectoral problems. The strongly promoted NPM principle of 'single-purpose organizations' came to be regarded as negative because it had led to a lot of horizontal specialization and fragmentation and to turf-wars among competing public organizations (Gregory 2003). The political and administrative leadership in those countries came up with several new coordinative measures that were easier to implement than reversing structural devolution: it established more cross-sector collaboration between political and administrative leaders in the central government apparatus. These took the form of programs, projects and networks, and there were even some structural mergers. The political and administrative leadership even tried to get the two main measures to interact, i.e. more hierarchical control of the different types of cross-sectoral collaboration and coordination.

Post-NPM reforms are in some ways more culturally oriented than the NPM reforms (Halligan 2007). That is particularly the case in Australia, where the concept of 'value-based management' has been important. While NPM ushered in a much more specialized cultural perspective, whereby every public organization should develop its own culture, the post-NPM message is that there should be more emphasis on a holistic perspective. The credo now is that civil servants and public institutions should be developing some kind of collective notion that they are in the same boat, and that there should be some kind of ethical standards and a focus on the ethos of the civil servants (Gregory 1999).

If we look at the 'old public administration', which existed in many countries up until the late 1970s, the system was simple and integrated in both a vertical and horizontal way. NPM had made that system much more complex, through the vertical and horizontal specialization process. But Weberian features from the old system were kept and blended with NPM, so that although it was a reform that was 
supposed to promote autonomy, it only partly delivered on that point. Nevertheless, we can say that NPM tilted the balance away from control and towards autonomy (Pollitt and Bouckaert 2004). When the post-NPM reforms came along, the balance tilted somewhat back towards more control. The post-NPM reforms play out more along the horizontal structural dimension, with more integration, including cultural integration. In other words they have added to and modified the NPM reforms, making the total system features more complex and certainly more hybrid. But the hybridity is of a different quality in the two reform waves, i.e. more disintegrated in NPM and more integrated in post-NPM, potentially leading to different tensions, challenges and effects.

\section{Adding complexity and hybridity: The Norwegian welfare administration reform}

The Norwegian reform context and the main feature of the reform

To take a closer look at the dynamics of transforming the civil service in a way that adds complexity and hybridity, we will describe and analyze how control and autonomy as well as other considerations are balanced in the largest Norwegian administrative reform ever, in the period 2001-2010: the reform of the labor and welfare administration. This reform incorporated central elements from both NPM and post-NPM, leading to more structural and cultural complexity and hybridity. We will both analyze how increased complexity and hybridity have emerged in the process and content of the reform and also relate this to the preliminary effects of the reform and the challenges it raises. ${ }^{2}$

Norway is a unitary, parliamentary and multi-party state that since the early 1970s has been ruled by minority governments, but this changed in 2005 when a center-left majority coalition came to power. Collectivist and egalitarian values are important, consensus-orientation is crucial, the level of internal conflicts is low, and corporatist arrangements are well developed (Christensen 2003).

Norway is seen as a rather reluctant reformer when it comes to taking NPM reforms on board. Its reform efforts all started with some symbolic adaptations to NPM in reform programs in the late 1980s, while the 1990s gradually brought more autonomy for agencies and state-owned enterprises, and devolution reforms of the immigration administration and regulatory agencies more broadly were launched in 2001 and 2003 respectively. From 2000, post-NPM elements started to emerge, in combination with NPM features, as seen in the police reform in 2000 and the hospital reform in 2002. Several attempts in 2004-2007 tried to modify the reform of the immigration administration in a more post-NPM direction (Christensen et al. 2007).

\footnotetext{
2 The data used is 60 personal interviews with top political and leaders in the Ministry of Social Inclusion and Labour, representatives of Parliament, and top leaders in the Norwegian Welfare and Labour Agency, but also a variety of public reports - internal documents, public commission reports and documents from the parliamentary debates.
} 
The comprehensive reform of the welfare administration was initiated in 2001, adopted in 2005, and after an interim period of a year, began implementation from 2006 through 2009. It's is affecting 15,000-20,000 civil servants on different levels and relates to $1 / 3$ of the total budget of the government. The main element in the reform is the following: it was decided that the employment administration, represented by the Directorate of Labour (DOL), should be merged with the National Insurance Administration (NIA) into one new labor and welfare agency (NAV) represented on all levels (Christensen et al. 2007). It was also decided that a new local frontline service should be organized - a one-stop shop — resulting from a new partnership between NAV and the locally based social services. The local partnership was meant to combine control and formalization with flexibility and variety, meaning that each municipality had to have a new coordinated and co-located welfare and labour office with a minimum of services included, but that they could decide on the leadership structure and eventually to add more services, combining standardization and potential variety.

The reform process was rather complicated and deviated from other reforms in one particular respect, namely, the unusual role of the parliament-the Storting (Christensen et al. 2007). Normally it is the political and administrative executive that initiates reforms, but in this case it was the Storting. ${ }^{3}$ The Storting expected the government to come up with a model involving one agency for labor and welfare. The government's initial proposal, as a response to the initiative from the Storting, however, was to keep most of the existing fragmented structure. The Storting sent the proposal back, resulting in a political defeat for the government. In the next phase the government established a public commission, mainly in order to use professional arguments to convince the Storting of its position. The commission also thought that basically a version of the established fragmented structure was the best solution. But the incoming minister in a merged Ministry for Labor and Social Affairs changed the course of action. Ignoring the commission's proposal, he worked closely with the Storting and got it to accept a proposal that implied a partial merger, keeping responsibility for social services in local government, but in a partnership with the two merged central agencies. The partial merger signaled increased complexity and hybridity.

Two of the three main goals of the reform are connected to NPM, namely increased efficiency and increased user-friendliness. The idea of the merger and local partnerships was to achieve economies of sale, while the new local partnership and the 'one-door policy' was designed to increase user-friendliness; this was also related to the third goal of getting more people into the workforce, particularly the multi-service users. NPM was also evident in the internal organization of the new central NAV agency: a large internal provider unit ('agency within an agency') was created, while the rest of the central NAV agency was to function as a kind of strategic purchaser (Askim et al. 2009). ${ }^{4}$ The new organization is also equipped with a performance management system.

\footnotetext{
${ }^{3}$ When the Storting is involved in reforms, it's normally related to either new/changing laws or budgetary questions. In this reform process, a lot of extra money was needed, but it was primarily more of an administrative reform than a content reform changing the laws. Since the then government was a minority government, it was, however, more open for initiatives and influence overall from the Storting.

${ }^{4}$ This feature is about to change in 2010 , through a reorganization merging the two units.
} 
The main background to the whole reform was to introduce more coordination mechanisms into a fragmented structure - a typical feature of post-NPM. The merger finally decided on was a watered-down version of the original plan, however, since it proved politically impossible to fully include the social services. Nevertheless, this was still the largest sectoral merger ever to have taken place in the Norwegian central administration, so the holistic aspect of the reform was certainly central.

The reform seems to tilt the balance in the direction of more central control and less local autonomy, but it is too early to say for sure. A new and stronger ministry, including all the relevant services has been established, together with a new and merged agency with a strong administrative apparatus that is also represented at the regional and local levels. This new organization has formed local partnerships with parts of the social services locally and will potentially be dominated by the NAV organization (Fimreite and Lægreid 2009). In addition, a further reorganization took place after the local partnerships had been established, creating regional pension units and county administrative units (back-offices), reducing the task portfolio, responsibilities and resources of the local offices.

Preliminary studies of effects of the reforms seem to indicate a varied result so far (Askim et al. 2010). Efficiency measures have been very much deemphasized, in accordance with a long-standing tradition in Norway. Some synergy features are evident, but all the employees kept their jobs, the new structure is very complicated and so far the reform has had an extra cost of 600 million Euros. The user satisfaction is somewhat down, which may both be interpretated as bad and good news, depending on the expectation related to such a vast reorganization (Hansen 2009). The multi-service users, the point of departure for the reform, seem to have improved their situation. Employees seem overall to support the reform, but struggle to settle in with a new structure, with lack of resources and competence, and a lot of environmental pressure (Andreassen and Fossestøl 2009).

Transformation, complexity and hybridity_process, reform content and effects

Overall the executive leadership scored low on control of the first phase of the process and its legitimacy took a blow when the Storting rejected its proposal for keeping the welfare administration divided and sent it back. In the next phase, the main actor was a clever and proactive minister who, as the leader of a reorganized ministry overseeing all three sectors involved-employment, national insurance/ pensions and social services - was in a strong position. Through skillful political negotiation he managed to get most of the other actors on board - the Storting, the sectors involved and the organization for the local authorities.

Neither the executive actors nor the main actors in the Storting scored high on rational calculation or clear organizational thinking. The main goals for the reform were decided on early on, but the weakness of this part of the process became evident when both sides, argued that their solution - a disintegrated and an integrated one, respectively — would further the same goals. The model finally chosen was also a complicated solution, combining increased coordination with control potential, with autonomy and new strong local units. It lacked clarity concerning the possible effects, and it was partly modified during the implementation process. The thinking was ambiguous, the resulting solution hybrid and the preliminary effects divided. 
The organizational model finally chosen reflects a tendency towards negotiation and compromise, i.e. a compromise was actually a main precondition for reaching a final decision. Often new complex structures contain elements that are directly connected to the diversity of the actors designing them, which was the case here. The incoming minister managed to resolve a stand-off between the executive and the parliament, by getting support for a compromise between control and autonomy. By merging two sector organizations and making local partnerships, he catered to the actors who wanted to see more coordination, but he also reassured the actors who still wanted strong central control, arguing that the merged agency would probably strengthen that control. In addition he also took account of the interests of actors who favored strong local government and maintaining the division of tasks between the central state and the municipalities, by establishing local partnerships and keeping the social services a local responsibility. The minister got a legitimate solution with hybrid features, which was seen as political necessary.

Our reform case also illustrates this increasing cultural complexity. Culturally speaking the challenges of this reform are huge, because it sets out to mold three different and distinct administrative cultures into a new identity and culture. The former employment service, which had been modernized and become more resultsoriented, was merged with the more traditional, rule-oriented Weberian culture of the national insurance service. The reform also brought a third factor into the cultural equation, the locally based and discretion-oriented social services. To create a common culture or identity has been challenging, also because structural complexity interacts with cultural complexity and hybridity, i.e. structural incongruence between the former agencies had to be dealt with at the same time as cultural integration and development of new competence (Askim et al. 2009).

The influence of a combination of environmental factors is also evident in this welfare reform. The reform certainly constituted a response to real problems of too many people on pensions and social benefits, creating efficiency problems. But it was not evident why such a large and complex reform was the answer to these problems. The minister's main symbolic card was 'local partnership', which sounded good and had the necessary ambiguity. It also combined central standards with local autonomy. All this made the model easier to sell politically.

\section{Conclusion}

Our case seems to support the notion of a kind of layering (Streeck and Thelen 2005) or sedimentation process (Olsen 2009) going on that implies that new reforms complement or supplement old reforms rather than replacing them. Old and new institutions co-exist and co-evolve even if they are founded on partly inconsistent principles. This means that rather than being dead and replaced by post-NPM reforms, NPM reforms are being modified and adjusted through the addition of new and different post-NPM reform measures. The result of such a process is increased complexity and hybridity in the organization of the public sector but also increased turbulence, because the trade-off and balance between different principles tends to change over time, between countries and across policy areas (Askim et al. 2009). 
Any shift in the balance between autonomy and control must be seen in the contested nature of administrative reforms and the somewhat limited understanding reformers have of the multi-functional nature of public sector organizations and competing institutional values, principles and interests (Olsen 2009). These characteristics tend to encourage a never-ending reform process that makes public sector organizations ever more complex and hybrid. This is not necessarily unhealthy but rather a systemic feature of public sector organizations in which one has to learn to live with partly conflicting principles, goals, structures and cultural values in a shifting environmental, cultural and structural context. Rather than looking at hybrid forms as some kind of an illness that needs to be cured we should regard it as a systemic feature that may have advantages of flexibility.

Precisely why this increased complexity and hybridity occurs is, however, contested. Our argument is that we have to look for a complex mixture of different driving forces. We cannot assume that reform agents have sufficient capability, cognitive capacity and power to act as rational actors. Their behaviour is constrained by different contextual features. Polity, culture and environmental features exert important constraints on deliberate organizational design (Christensen and Lægreid 2001a, 2007b). There is no agreed upon empirical administrative theory specifying under which conditions one set of factors has greater explanatory power than other factors or how their mutual influence can be understood (Olsen 2007). We embrace the growing claim that context matters (March 2008), but there is still no good theory of context that specifies under what conditions different contexts matter (Pollitt 2003).

The Norwegian welfare administration reform focused was about introducing more coordination. But it does not use a 'pure' set of post-NPM principles. Rather the reform was decided on after a complicated process of compromise by combining NPM and post-NPM reform elements in a complex mix, albeit with a slant towards post-NPM features. Formal vertical and horizontal reintegration or de-specialization is used, blended with NPM instruments for performance management systems, purchaser-provider elements, a devolution element like strong local welfare offices, etc. The reform was also modified after it was decided on, potentially increasing complexity and hybridity still further, illustrated by increasing tension between control and local autonomy.

Overall, the reform studied is both atypical and typical in a comparative national and international perspective. It is atypical in a national sense that the political leadership had to struggle for control and had, at least to some degree, to submit to the demands of the Storting. This was one of the main reasons why the process became more complex, because the minister had to strike a compromise to get the reform through. In an international comparative perspective such features are more common in countries with parliamentary democracies with coalition governments and more political turbulence, than in Anglo-Saxon countries with more 'elective dictatorship' (Hood 1996).

The process is typical in scoring rather low on clear organizational thinking, which is changing, ambiguous and not well founded, despite the inclusion of experts. Actors share common goals but propose widely differing routes for arriving at them. This seem to be typical for reform processes in many countries, because the complexity in societal and public structures, cultures and interests that should be 
catered to are ever increasing (Pollitt and Bouckaert 2004). Again, hybridity seems to vary between types of political-administrative systems, as indicated above, or also among policy areas, as are the challenges for rational calculation.

Open Access This article is distributed under the terms of the Creative Commons Attribution Noncommercial License which permits any noncommercial use, distribution, and reproduction in any medium, provided the original author(s) and source are credited.

\section{References}

Allison, G. T. (1971). Essence of decision. Boston: Little, Brown.

Anderson, P. (1999). Complexity theory and organizational science. Organizational Science, 10(3), $216-232$.

Andreassen, T. A., \& Fossestøl, K. (2009). Om iversetting ved lokale NAV-kontor: Å utvikle en helhetlig og brukerrettet forvaltning - oppdragsstyring eller samstyring? (On implementiation at local NAV offices: on developing a holistic and user-directed administration-central contractual control or collaborative steering?). Tidsskrift for Velferdsforskning, 12(3), 168-179.

Askim, J., Christensen, T., Fimreite, A. L., \& Lægreid, P. (2009). How to carry out joined-up government reforms: lessons from the Norwegian Welfare Reform. International Journal of Public Administration, 32, 1006-1025.

Askim, J., Christensen, T., Fimreite, A. L., \& Lægreid, P. (2010). How to assess administrative reform? Investigating the adoption and preliminary impacts of the Norwegian welfare administration reform. Public Administration, 88(1), 232-246.

Boin, A., \& Christensen, T. (2008). The development of public institutions: reconsidering the role of leadership. Administration \& Society, 40(3), 271-297.

Boston, J., Martin, J., Pallot, J., \& Walsh, P. (1996). Public management: The New Zealand model. Auckland: Oxford University Press.

Brunsson, N. (1989). The organization of hypocrisy. Talk, decisions and actions in organizations. Chichester: Wiley.

Brunsson, N., \& Olsen, J. P. (1993). The reforming organization. London: Routledge.

Christensen, T. (2003). Narrative of Norwegian governance: elaborating the strong state. Public Administration, 81(1), 163-190.

Christensen, T., \& Lægreid, P. (2001a). A transformative perspective on administrative reforms. In T. Christensen \& P. Lægreid (Eds.), New public management. The transformation of ideas and practice. Aldershot: Ashgate.

Christensen, T., \& Lægreid, P. (2001b). New public management-undermining political control? In T. Christensen \& P. Lægreid (Eds.), New public management. The transformation of ideas and practice. Aldershot: Ashgate.

Christensen, T., \& Lægreid, P. (2007a). The whole-of-government approach to public sector reform. Public Administration Review, 67(6), 1059-1066.

Christensen, T., \& Lægreid, P. (2007b). Introduction-theoretical approach and research questions. In T. Christensen \& P. Lægreid (Eds.), Transcending new public management. Aldershot: Ashgate.

Christensen, T., Fimreite, A. L., \& Lægreid, P. (2007). Reform of the employment and welfare administrations - the challenges of co-coordinating diverse public organizations. International Review of Administrative Sciences, 73(3), 389-409.

Cyert, R. M., \& March, J. G. (1963). A behavioral theory of the firm. Englewood Cliffs: Prentice-Hall. Czarniawska, B., \& Sevón, G. (Eds.). (1996). Translating organizational change. Berlin: De Gruyter.

Daft, R. L. (1992). Organization theory and design. St. Paul: West Publishing.

Dahl, R. A., \& Lindblom, C. E. (1953). Politics, economics, and welfare. New York: Harper \& Row.

DiMaggio, P. J., \& Powell, W. W. (1983). The iron cage revisited: institutional isomorphism and collective rationality in organizational fields. American Sociological Review, 48(2), 147-160.

Egeberg, M. (2003). How bureaucratic structure matters: An organizational perspective. In B. G. Peters \& J. Pierre (Eds.), Handbook of public administration. London: Sage.

Farazmand, A. (2002). Modern organizations: Theory and practice. Westport: Praeger. 
Fimreite, A. L., \& Lægreid, P. (2009). Reorganization of the welfare state administration: partnerships, networks and accountability. Public Management Review, 11(3), 281-297.

Gregory, R. (1999). Social capital theory and administrative reform: maintaining ethical probity in public service. Public Administration Review, 59(1), 63-75.

Gregory, R. (2001). Transforming governmental culture: A sceptical view of new public management. In T. Christensen \& P. Lægreid (Eds.), New public management. The transformation of ideas and practice. Aldershot: Ashgate.

Gregory, R. (2003). All the King's horses and all the King's men: putting New Zealand's public sector back together again. International Public Management Review, 4(2), 41-58.

Gulick, L. (1937). Notes on the theory of organizations. With special reference to government. In L. Gulick \& L. Urwin (Eds.), Papers on the science of administration. New York: A. M. Kelley.

Halligan, J. (2001). The process of reform in the era of transformation. In T. Christensen \& P. Lægreid (Eds.), New public management. The transformation of ideas and practice. Aldershot: Ashgate.

Halligan, J. (2006). The reassertion of the centre in a first generation NPM system. In T. Christensen \& P. Lægreid (Eds.), Autonomy and regulation. Coping with agencies in the modern state. London: Edward Elgar.

Halligan, J. (2007). Reform design and performance in Australia and New Zealand. In T. Christensen \& P. Lægreid (Eds.), Transcending new public management. Aldershot: Ashgate.

Hansen, H. T. (2009). Brukererfaringer med NAV: NAV på rett vei? En surveybasert brukerundersøkelse (User experiences with NAV: NAV on the right course? A surveybased user analysis). Tidsskrift for Velferdsforskning, 12(3), 207-227.

Hood, C. (1996). Exploring Variations in Public Management Reform of the 1980s'. In H. A. G. M. Bekke, J. L. Perry \& T. A. J. Toonen (Eds.), Civil Service Systems. Bloomington, IN: Indiana University Press.

Kaufman, H. A. (1960). The forest ranger. A study in administrative behavior. Oxford: Oxford University Press.

Kettl, D. F. (2006). Modernizing government: the way forward-a comment. International Review of Administrative Sciences, 72(3), 313-318.

Kickert, W. J. M. (2001). Public management of hybrid organizations: governance of quasi-autonomous organizations. International Public Management Journal, 4(2), 135-150.

Koppell, J. G. S. (2003). The politics of quasi-government. Hybrid organizations and the dynamics of bureaucratic control. Cambridge: Cambridge University Press.

Krasner, S. D. (1988). Sovereignty. An institutional perspective. Comparative Political Studies, 21(1), 66-94.

Lægreid, P., Roness, P. G., \& Rubecksen, K. (2007). Modern management tools in state agencies: the case of Norway. International Public Management Journal, 10(4), 387-413.

Lan, Z., \& Rainey, H. G. (1992). Goals, rules, and effectiveness in public, private and hybrid organizations: more evidence on frequent assertions about differences. Journal of Public Administration Research and Theory, 2(1), 5-28.

Lawrence, P. R., \& Lorsch, J. W. (1967). Organization and environment. Managing differentiation and integration. Boston: Graduate School of Business Administration, Harvard University.

Light, P. C. (1997). The tides of reform: Making government work 1945-1995. New Haven: Yale University Press.

Lynn, L. E., Jr. (2006). Public management old and new. New York: Routledge.

March, J. G. (2008). Exploratations in organizations. Stanford: Stanford University Press.

March, J. G., \& Olsen, J. P. (1976). Ambiguity and choice in organizations. Bergen: Universitetsforlaget.

March, J. G., \& Olsen, J. P. (1983). Organizing political life. What administrative reorganization tells us about government. American Political Science Review, 77, 281-297.

March, J. G., \& Olsen, J. P. (1989). Rediscovering institutions: The organizational basis of politics. New York: The Free Press.

Meyer, J. W., \& Rowan, B. (1977). Institutionalized organizations: formal structure as myth and ceremony. The American Journal of Sociology, 83, 340-363.

Minkoff, D. C. (2002). The emergence of hybrid organizational forms: combining identity-based service provision and political action. Nonprofit and Voluntary Sector Quarterly, 31(3), 377-401.

Olsen, J. P. (1992). Analyzing institutional dynamics. Staatswissenschaften und Staatspraxis, 2, $247-271$.

Olsen, J. P. (2007). The ups and downs of bureaucratic organization. The Annual Review of Political Science, 11, 13-37.

Olsen, J. P. (2009). Change and continuity: an institutional approach to institutions of democratic government. European Political Science Review, 1(1), 3-32.

Pollitt, C. (2003). The essential public manager. Maidenhead: Open University Press. 
Pollitt, C. (2009). Complexity theory and evolutionary public administration: A skeptical afterword. In G. Teisman, A. Van Buuren, \& L. Gerrits (Eds.), Managing complex governance systems. London: Routledge.

Pollitt, C., \& Bouckaert, G. (2004). Public management reform: A comparative analysis (2nd ed.). Oxford: Oxford University Press.

Pollitt, C., van Thiel, S., \& Homburg, V. (Eds.). (2007). New public management in Europe. Basingstoke: Palgrave.

Røvik, K. A. (1996). Deinstitutionalization and the logic of fashion. In B. Czarniawska \& G. Sevon (Eds.), Translating organizational change. New York: De Gruyter.

Røvik, K. A. (2002). The secrets of the winners: Management ideas that flow. In K. Sahlin-Andersson \& L. Engwall (Eds.), The expansion of management knowledge-carriers, flows and sources. Stanford: Stanford University Press.

Sahlin-Anderson, K. (2001). National, international and transnational construction of new public management. In T. Christensen \& P. Lægreid (Eds.), New public management. The transformation of ideas and practice. Aldershot: Ashgate.

Sahlin-Andersson, K. (1996). Imitating by editing success. In B. Czarniawska \& G. Sevon (Eds.), Translating organizational change. New York: De Gruyter.

Scott, W. R. (2007). Institutions and organizations (3rd rev. ed.). Thousands Oaks: Sage.

Scott, W. R., \& Davies, G. (2006). Organizations and organizing: Rational, natural and open systems perspectives (6th rev ed.). NJ: Prentice Hall.

Selznick, P. (1957). Leadership in administration. New York: Harper \& Row.

Simon, H. (1957). Administrative behaviour. New York: Macmillan.

Streeck, W., \& Thelen, K. (2005). Beyond continuity. Oxford: Oxford University Press.

Teisman, G., Van Buuren, A., \& Gerrits, L. (Eds.). (2009). Managing complex governance systems. London: Routledge.

Weaver, B. K., \& Rockman, B. A. (1993). Assessing the effects of institutions. In R. K. Weaver \& B. A. Rockman (Eds.), Do institutions matter? Government capabilities in the United States and abroad. Washington, DC: The Brookings Institution.

Williamson, O. E. (1991). Comparative economic organization: the analysis of discrete structural alternatives. Administrative Science Quarterly, 36, 269-296.

Tom Christensen is professor in public policy and administration at the Department of Political Science, University of Oslo and senior researcher (part time) at Uni Rokkan Centre, Bergen.

Per Lægreid is professor at the Department of Administration and Organization Theory, University of Bergen and senior researcher (part time) at Uni Rokkan Centre, Bergen. 